\title{
Resiliency and quality of life trajectories after injury
}

\author{
Ben L. Zarzaur, MD, MPH${ }^{\star}$, Teresa M. Bell, Ph.D. ${ }^{*}$, and Stephen A. Zanskas, Ph. ${ }^{\dagger}$ \\ *Indiana University School of Medicine, Department of Surgery \\ tUniversity of Memphis, Department of Counseling, Educational Psychology and Research
}

\begin{abstract}
Background-Injury can greatly impact patients' long-term quality of life. Resilience refers to an individual's ability to positively adapt after facing stress or trauma. The objective of this study was to examine the relationship between pre-injury resiliency scores and quality of life after injury.
\end{abstract}

\begin{abstract}
Methods-225 adults admitted with an injury severity score $>10$ but without neurological injury were included. The SF-36 was administered at the time of admission and repeated at 1,2,4 and 12 months after injury. The Connor-Davidson Resilience Scale was completed at admission and scores were categorized into high resiliency or not high resiliency. Group based trajectory modeling was used (GBTM) to identify distinct recovery trajectories for physical component scores (PCS) and mental component scores (MCS) of the SF-36. Multinomial logistic regression was used to determine whether baseline resiliency scores were predictive of PCS and MCS recovery trajectories.
\end{abstract}

Results-Age, race, gender, mechanism of injury, Charlson Comorbidity Index, Injury Severity Score, presence of hypotension on admission, and insurance status were not associated with High Resiliency. Compared to those who made $<\$ 10,000$ per year, those who made more than $\$ 50,000$ per year had higher odds of being in the High Resilience group (OR 10.92, 95\% CI 2.58-46.32). Three PCS and 5 MCS trajectories were identified. There was no relationship between resilience and PCS trajectory. However, patients with high resiliency scores were $85 \%$ less likely to belong to trajectory 1 , the trajectory that had the lowest mental health scores over the course of the study.

Corresponding Author: Ben L. Zarzaur, MD, MPH, Associate Professor of Surgery, Indiana University School of Medicine, 702 Rotary Circle, Room 022b, Indianapolis, IN 46204, bzarzaur@iupui.edu, Office: 317-274-7422, Fax: 317-274-7426.

Ben L. Zarzaur, MD, MPH, Indiana University School of Medicine, Department of Surgery, bzarzaur@iupui.edu

Teresa M. Bell, PhD, Indiana University School of Medicine, Department of Surgery, terebell@iupui.edu

Stephen A. Zanskas, PhD, University of Memphis, Department of Counseling, Educational Psychology and Research, szanskas@memphis.edu

Presentation Disclosure:

This work was presented as a poster at the $74^{\text {th }}$ annual meeting of the American Association for the Surgery of Trauma, September 912, 2015, in Las Vegas, Nevada.

Author Contributions:

BLZ - Study conception; study design; data collection; data interpretation; writing; critical revisions

TMB - Data analysis; data interpretation; writing; critical revisions

SAZ - Study conception; data interpretation; critical revisions

Funding Disclosure:

Research reported in this publication was supported by National Institute of General Medical Sciences of the National Institutes of Health under award number K23GM084427. The content is solely the responsibility of the authors and does not necessarily represent the official views of the National Institutes of Health. 
Follow-up for the study was $93.8 \%$ for month $1,82.7 \%$ for month $2,69.4 \%$ for month 4 and $63.6 \%$ for month 12 .

Conclusion-Patient resiliency predicts quality of life after injury in regards to mental health with over $25 \%$ of patients suffering poor mental health outcome trajectories. Efforts to teach resiliency skills to injured patients could improve long-term mental health for injured patients. Trauma centers are well positioned to carry out such interventions.

Level of Evidence-Level III

\section{Keywords}

Post-traumatic growth; Resiliency; Quality of life after injury; Recovery after injury

\section{BACKGROUND}

Over the last half-century, the development of trauma centers and advances in the care of injured patients has been associated with increased survivorship for the injured with an estimated 63 million injury survivors in the United States every year $(1,2)$. With such a large number of injury survivors, there has been increased focus on long-term outcomes, including quality of life. It has long been known that injured patients suffer an acute drop in quality of life and functional ability for at least a year after injury $(3,4)$. However, recent studies have shown that the response to critical illness and injury in terms of mental and physical recovery is not homogenous (5-7). Some patients have a near complete mental and physical recovery. Others, however, suffer ongoing or recurrent issues during their recovery. Patients who are resistant to the effects of injury or who are able to recover from devastating injuries or experiences are said to follow resilient trajectories.

According to resilience theory (8), resiliency is the ability of a person who suffers psychological or physical injury to withstand or overcome the negative effects of the injury and to return to, at least, pre-injury baseline function or, possibly, improved function. Importantly, resilience is not only associated with inherent personality traits, but it is also associated with skills that can be learned (9). Because resilience is made up of learned skills, identifying those with low resilience at the time of exposure to a traumatic event could allow for resilience specific training in the expectation that patients could have improved longterm outcomes. However, before designing interventions aimed at improving resilience, an association between low resilience and poor outcomes needs to be established. Previous studies indicate that resilience is associated with lower risk of post-traumatic stress disorder among veterans, improved quality of life in patients with spinal cord and traumatic brain injury, and less depression among survivors of violence (10-13). However, there are few studies focused on moderately to severely injured patients without brain or spinal cord injury who are treated at civilian trauma centers. Further, there is a paucity of data regarding the use of commonly available resiliency scales among injury survivors without brain or spinal cord injury. The purpose of this study was to examine the relationship between baseline resiliency scores and overall quality of life after injury in patients without neurologic injury who are treated at a civilian trauma center. Further, we sought to determine predictors of low resilience in this cohort. 


\section{METHODS}

\section{Data Source}

This is a retrospective study of a previously performed prospective cohort study that followed traumatically injured patients for 12 months after injury and is described elsewhere (5). Briefly, patients ages 18 years or older who had an injury severity score greater than 10 , but without traumatic brain injury or spinal cord injury were eligible to enroll in the study. The study took place at an urban, academic, Level I trauma center in Memphis, Tennessee. Patients were enrolled from January 2009 - December 2011 and follow-up was completed in December 2012. A baseline quality of life survey (SF-36) was administered shortly after admission and repeated at 1, 2, 4 and 12 months after injury. Demographic and clinical variables were collected on patient age, gender, race, insurance status, annual income, comorbidities, injury severity, injury mechanism, and shock upon hospital arrival.

\section{Primary Independent Variable}

The primary independent variable of interest was resiliency, which was scored at baseline using the Connor-Davidson Resilience Scale - 10 (14). The Connor-Davidson Resilience Scale - 10 is based on the original scale proposed by Connor and Davidson in 2003 (14) and uses 10 questions from the original scale. The shorter version is highly correlated with the original scale and it is able to discriminate between those with low and high resilience (14). The Connor-Davidson Resilience Scale - 10 has been validated in the general population and has been used in populations that have suffered a traumatic event $(15,16)$. Mean scores were 31.8 (Standard Deviation $=5.4$ ) and population quartile scores were 29 for the 25 th $\%$, 32 for the 50th \%, and 36 for the 75th \% (14). Based on these data, resiliency scores were classified into categories of high resiliency (scores 33-40) and not high resiliency (scores less than 32) for the analysis. Of the 500 patients recruited in the original study (5), the final 225 consecutive patients enrolled received the Connor Davidson Resiliency Scale - 10 during the index admission.

\section{Outcome Variables}

We used the Short Form (36) Health Survey (SF-36) to evaluate quality of life after injury, which has been validated and widely used in the injured patient population. The SF-36 produces an 8-scale profile of health that can be used to calculate summary physical and mental health composite scores. Both the physical and mental composite scores were used to generate the outcome variables in the analysis. Due to the longitudinal study design, we used 12 month trajectories of mental and physical health as the outcome of interest. We previously performed group-based trajectory analysis with two different outcome variables, the SF-36 physical composite score (PCS) and the SF-36 mental composite score (MCS) (5). The primary advantage of this type of analysis is that it is able to classify a longitudinal outcome as distinct trends among subgroups of a heterogeneous population. Each study participant was assigned to a single trajectory for each respective outcome through the use of posterior probabilities. The model identified three physical health trajectory subgroups and 5 mental health trajectory subgroups (Figure 1). 
The objective of this study was to determine whether patient resiliency was associated with courses of mental and physical health trajectories after traumatic injury. We examined demographic and clinical characteristics between patients with high resiliency levels and not high resiliency levels. Differences in the baseline characteristics were assessed using Student's $t$ test for continuous variables and chi square tests for categorical variables.

Patient characteristics predictive of high resiliency were evaluated using multivariate logistic regression. For this analysis, a binary resilience variable was used as the dependent variable. We a priori planned to use a three level categorical variable for resilience. However, after examining the distribution of the data we noted that there were to few patients in the lowest resilience group. Therefore we decided to utilize a binary variable for this analysis. The logistic regression model included variables on patient age, race, gender, Charleston Comorbidity Index (CCI), individual annual income, mechanism of injury, injury severity score, and hypotension.

Two multinomial regression models were used to determine whether patient resiliency was predictive of physical and mental health trajectory over the 12 month period following traumatic injury. In each of these models, the trajectory group with the highest physical and mental health scores was used as the reference group. For the physical health trajectory analysis, trajectory 3 was used as the reference group to which trajectories 1 and 2 were compared. Trajectory 5 was used as the reference group for the mental health trajectory analysis and comparisons were made with trajectories 1,2,3, and 4. The models adjusted for patient age, race, gender, insurance status, Charleston Comorbidity Index (CCI), individual annual income, mechanism of injury, injury severity score, and hypotension. Odds ratios and $95 \%$ confidence intervals are reported.

Four logistic regression models were used to examine whether resiliency predicted PTSD and depression at 4 months and 12 months after injury. Each of these models controlled for patient age, race, gender, insurance status, CCI, individual annual income, mechanism of injury, ISS, hypotension, and PCS trajectory. Additionally, depression at 4 months and 12 months was adjusted for in the PTSD models at the respective time points. PTSD was also adjusted for in the depression models. Odds ratios and 95\% confidence intervals are reported. SAS 9.4 (Cary, NC) was used for all analyses.

\section{RESULTS}

There were 225 patients who were enrolled in the prospective cohort following moderate to severe non-neurologic injury who also had resilience scored at baseline using the ConnorDavidson Resilience Scale - 10. The characteristics of the entire cohort are displayed in Table 1. The patients were mostly 18-35 (53.3\%), male (58.7\%), non-minority (52.0\%), with very low income (49.8\% with annual individual income below $\$ 10,000)$, and with moderate injury severity (40.7\% with ISS 16-24). Most were victims of a blunt trauma mechanism (72.9\%) and nearly $63 \%$ had some type of health insurance. Patients were categorized based on the scores on the Connor-Davidson Resilience Scale - 10 as having either high resiliency or not having high resiliency. There were 106 classified as not having 
high resiliency (47.1\%) and $119(52.9 \%)$ as high resiliency. When the two groups were compared based on demographic and injury related information there were no significant differences.

Next, we examined the relationship between demographic and injury related factors and the probability of belonging to the High Resiliency group using logistic regression. Age, race, gender, mechanism of injury, Charlson Comorbidity Index, Injury Severity Score, presence of hypotension on admission, and insurance status were not associated with High Resiliency. However, there was a significant relationship between individual income and High Resilience. Compared to those who made $<\$ 10,000$ per year, those who made more than $\$ 50,000$ per year had higher odds of being in the High Resilience group (OR 10.92, 95\% CI 2.58-46.32) (Table 2).

We then turned our attention to the quality of life trajectories followed by the patients in this cohort as determined using the SF-36. We have previously demonstrated that patients in this cohort follow one of 3 different Physical Component Score Trajectories and 5 different Mental Component Score Trajectories (Figure 1) (5). For both the Physical Component Score and the Mental Component Score trajectories we determined which trajectory demonstrated the highest level of function. The trajectory with the highest level of function was used as the comparator in multinomial regression. For the Physical Component Score Trajectories we utilized trajectory 3 as the outcome reference group and for the Mental Component Score trajectory 5 was used as the outcome reference group.

In Table 3, the results of the multinomial regression for the Physical Component Scores are shown. The only factor associated Physical Component Scores was individual income.

Compared to those who made $<\$ 10,000$ per year, those who made $>\$ 50,000$ per year were $92 \%$ less likely to belong to trajectory 1 and $90 \%$ less likely to belong to trajectory 2 (Trajectory 1: OR 0.08, 95\% CI 0.00-1.30; Trajectory 2: OR 0.10, 95\% CI 0.02-0.49). There was no relationship between resilience level and physical quality of life trajectory.

However, for the Mental Component Score trajectories, resilience was associated with the outcome (Table 4). Patients with high resiliency scores were $85 \%$ less likely to belong to trajectory 1 , the trajectory that consistently had the lowest mental health scores over the course of the study. Age and income were also predictive of patients belonging to mental health trajectory 1 . Patients ages 46-60 were more likely to belong to this trajectory and patients with incomes over $\$ 10,000$ were less likely to belong to trajectory 1 . Having an injury severity score 35 or greater also increased the likelihood of belonging to trajectory 1 . Patients with higher incomes were also less likely to belong to trajectory 3 , which shows an initial decline in mental health followed by recovery, and trajectory 4 , which demonstrates an initial decrease in mental health followed by continual decline. Race, gender, insurance status, comorbidities, and mechanism of injury were not predictive of mental health recovery trajectories.

Logistic regression analyses found that high resiliency has no relationship with PTSD at 4 months but is associated with increased risk for PTSD at 12 months (OR 3.18, 95\% CI 1.029.90) (Table 5). Depression is associated with increased risk of PTSD at both 4 and 12 
months (OR 14.57, 95\% CI 4.20-50.58; OR 20.37, 95\% CI 4.23-97.98, respectively). High resiliency is associated with decreased risk of depression at both 4 and 12 months (OR 0.35, 95\% CI 0.15-0.879; OR 0.18, 95\% CI 0.06-0.56). PTSD is associated with increased risk of depression at 4 and 12 months (OR 15.07, 95\% CI 4.39-51.79; OR 20.28, 95\% CI 4.3794.14).

\section{DISCUSSION}

In this prospective cohort study of civilians who suffered moderate to severe non-neurologic injury we found that those with low levels of resilience were much more likely to follow a poor post-injury mental health trajectory compared to those who had higher levels of resilience at baseline. High resiliency was associated with lower risk of depression following injury, but higher risk of delayed PTSD after injury. Further, patients who had higher baseline income were more likely to have higher resilience compared to those in the lowest income strata, no matter the level of resilience. Interestingly, there was no relationship between physical recovery and baseline resilience. This study adds to and extends the existing literature on the subject of resilience and post-traumatic recovery.

Prior work from our group as well as from others demonstrates that after traumatic events injury survivors follow various trajectories, particularly in terms of mental health $(10-13$, 18 -20). From a psychological standpoint, injury survivors can follow one of 5 different recovery trajectories in the year following injury $(5,10-13,18-20)$ (Mental Health Composite Scores - Figure 1). Injury survivors can have an initial decrease in psychological well being immediately following injury with either rapid recovery or prolonged psychological dysfunction. Others suffer a delayed decline in their psychological health several months after injury. Some patients follow a chronically depressed psychological health trajectory. Finally, there are those who have high levels of psychological well being immediately after injury and they are able to maintain these levels of high psychological functioning throughout the post-injury recovery period. In this study, we used this resilient trajectory (Mental Health Composite Score - Trajectory 5 in Figure 1) as the comparator in the multinomial regression analysis. The results of this analysis indicated that compared to those in the worst functioning trajectory (Mental Health Composite Score - Trajectory 1 in Figure 1) that the patients in Trajectory 5 were $85 \%$ more likely to have high resilience scores.

The existence of these varied phenotypes makes it difficult to predict what type of recovery a particular individual may experience. Psychological resilience is thought to play a role in moderating the effect of traumatic events on the mental health of an injury survivor (18 20). Resilience's role in moderating poor outcomes among war veterans as well as those with brain or spinal cord injury has been well documented $(10-13)$.

The extent to which resilience can be modified is an area of specific interest.. The exact psychological constructs that make up "resilience" have not been delineated. This makes targeting interventions towards improving resilience more difficult. Multimodality interventions are proposed to be more effective than interventions that are unifocal. Interventions aimed at enhancing the natural recovery that occurs as a result of post- 
traumatic growth as well as those that take a more active, therapeutic approach have been tried and have been shown to be successful. However, resilience appears to be modifiable and there are clearly interventions that can teach injury survivors the skills associated with resilience and good mental health outcomes $(21-25)$.

There is a paucity of data form from controlled trials of interventions to improve in the general injury survivor population. However, there are some promising early studies. In a randomized controlled trial of United States veterans, Kent and colleagues developed an intervention that was delivered in 12 weekly 90 -minute group sessions. This intervention was based on the positive psychology movement. The initial sessions were focused on developing awareness of positive emotions and social connectedness. In later sessions, participants were encouraged to use these skills when they were discussing their traumatic event or when they were experiencing symptoms associated with Post-Traumatic Stress Disorder. The authors found that compared to controls, participants had improved emotional health and reduced symptoms (26). Interventions based on cognitive behavioral therapy have also shown promise at improving resiliency and reducing psychological symptoms after motor vehicle crashes $(27-29)$. In these studies cognitive behavioral therapy techniques are were used for varying amounts of time to help the injured patients explore areas where they have been resilient in the past and then to explore ways to apply those strengths to their current situation. Results from these studies indicate that cognitive behavioral therapy techniques can reduce symptoms of anxiety and symptoms related to post-traumatic stress disorder $(27-29)$.

The current study does have limitations. The cohort is from a single institution and may not be generalizable to a broader population. While follow-up for the cohort was robust, there is the potential that follow-up bias could effect the study outcomes. However, when we compared the patients for whom we had complete follow-up to those without complete follow-up we found that there were no clinically significant differences. We also introduced the resiliency scale after recruiting 275 patients. It is possible that the 225 patients included in this study were different in some way to the overall study population. We compared the patients who were given the resiliency questions compared to those who did not receive the questions. There were no significant differences based on demographics or injury characteristics between the two groups. It is also possible that the measure we used for resilience may have a ceiling effect meaning that there might be small differences in resilience that we could not detect with the current measure. Further, we chose accepted cut points to determine high levels of resilience. However, is possible that through categorizing the variables using this cut points we may have lost valuable information regarding the relationship between outcomes and resilience. Because we were unable to measure resilience prior to injury it is possible that the scores on the Connor-Davidson Resilience Scale -10 were influenced by the injury event. The presence of variability between the baseline resilience scores measured after injury and the scores that would have been obtained if there were no injury is an inherent limitation of the data. However, the scale has been used in other traumatically injured patients, specifically those with spinal cord and brain injuries, and baseline scores obtained soon after injury are thought to reflect the best measure of baseline resilience available to researchers $(16-18)$. 
Despite these limitations there are some clear conclusions that can be drawn from this study. Over $25 \%$ of injured patients have a poor mental health trajectory after injury. Injury survivors with high resiliency scores at baseline are more likely to follow a favorable postinjury psychological trajectory. Measurement of resilience at baseline is practical in nonneurologically injured patients and can identify those with less than ideal coping skills.. Trauma centers are well positioned to carry out interventions to teach resiliency skills to vulnerable injured patients in order to improve long-term quality of life. This may be particularly important in the setting of increased survivorship associated with modern trauma center care.

\section{References}

1. WISQARS [database online]. Atlanta, GA: Centers for Disease Control National Center For Injury Prevention and Control; Available at: http://wisqars.cdc.gov:8080/costT/cost_Part1_Intro.jsp/ [Accessed January 23, 2014]

2. MacKenzie EJ, Rivara FP, Jurkovich GJ, Nathens AB, Frey KP, Egleston BL, Salkever DS, Scharfstein DO. A national evaluation of the effect of trauma-center care on mortality. N Engl J Med. 2006; 354(4):366-78. [PubMed: 16436768]

3. Holbrook TL, Anderson JP, Sieber WJ, Browner D, Hoyt DB. Outcome after major trauma: 12month and 18-month follow-up results from the Trauma Recovery Project. J Trauma. 1999; 46(5): 765-71. [PubMed: 10338392]

4. Michaels AJ, Michaels CE, Moon CH, Smith JS, Zimmerman MA, Taheri PA, Peterson C. Posttraumatic stress disorder after injury: impact on general health outcome and early risk assessment. J Trauma. 1999; 47(3):460-467. [PubMed: 10498298]

5. Zarzaur BL, Bell T. Trajectory subtypes after injury and patient-centered outcomes. J Surg Res. 2016; 202(1):103-10. [PubMed: 27083954]

6. Bell TM, Wang J, Nolly R, Ozdenerol E, Relyea G, Zarzaur BL. Predictors of functional limitation trajectories after injury in a nationally representative U.S. older adult population. Ann Epidemiol. 2015; 25(12):894-900. [PubMed: 26481503]

7. Harcombe H, Langley J, Davie G, Derrett S. Functional status following injury: what recovery pathways do people follow? Injury. 2015; 46(7):1275-80. [PubMed: 25920372]

8. Richardson GE. The metatheory of resilience and resiliency. J Clin Psychol. 2002; 58:307-321. [PubMed: 11836712]

9. Newman R. APA's resilience initiative. Prof Psychol: Res Pract. 2005; 36:227-229.

10. Andersen SB, Karstoft KI, Bertelsen M, Madsen T. Latent trajectories of trauma symptoms and resilience: the 3-year longitudinal prospective USPER study of Danish veterans deployed in Afghanistan. J Clin Psychiatry. 2014; 75(9):1001-8. [PubMed: 25188895]

11. Skogstad L, Tøien K, Hem E, Ranhoff AH, Sandvik L, Ekeberg Ø. Psychological distress after physical injury: a one-year follow-up study of conscious hospitalised patients. Injury. 2014; 45(1): 289-98. [PubMed: 23103082]

12. McCauley SR, Wilde EA, Miller ER, Frisby ML, Garza HM, Varghese R, Levin HS, Robertson CS, McCarthy JJ. Preinjury resilience and mood as predictors of early outcome following mild traumatic brain injury. J Neurotrauma. 2013; 30(8):642-52. [PubMed: 23046394]

13. Bonanno GA, Kennedy P, Galatzer-Levy IR, Lude P, Elfström ML. Trajectories of resilience, depression, and anxiety following spinal cord injury. Rehabil Psychol. 2012; 57(3):236-47. [PubMed: 22946611]

14. Connor KM, Davidson JR. Development of a new resilience scale: the Connor-Davidson Resilience Scale (CD-RISC). Depress Anxiety. 2003; 18(2):76-82. [PubMed: 12964174]

15. Campbell-Sills L, Forde DR, Stein MB. Demographic and childhood environmental predictors of resilience in a community sample. J Psychiatric Research. 2009; 43(12):1007-12.

16. Connor KM. Assessment of resilience in the aftermath of trauma. J Clin Psychiatry. 2006; 67(Suppl 2):46-9. 
17. Shin JI, Chae JH, Min JA, Lee CU, Hwang SI, Lee BS, Han SH, Ju HI, Lee CY. Resilience as a possible predictor for psychological distress in chronic spinal cord injured patients living in the community. Ann Rehabil Med. 2012; 36(6):815-820. [PubMed: 23342314]

18. Wingo AP, Fani N, Bradley B, Ressler KJ. Psychological resilience and neurocognitive performance in a traumatized community sample. Depress Anxiety. 2010; 27(8):768-74. [PubMed: 20186970]

19. deRoon-Cassini TA, Mancini AD, Rusch MD, Bonanno GA. Psychopathology and resilience following traumatic injury: a latent growth mixture model analysis. Rehabil Psychol. 2010; 55(1): 1-11. [PubMed: 20175629]

20. Norris FH, Tracy M, Galea S. Looking for resilience: understanding the longitudinal trajectories of responses to stress. Soc Sci Med. 2009; 68(12):2190-8. [PubMed: 19403217]

21. Diab M, Peltonen K, Qouta SR, Palosaari E, Punamäki RL. Effectiveness of psychosocial intervention enhancing resilience among war-affected children and the moderating role of family factors. Child Abuse Negl. 2015; 40:24-35. [PubMed: 25534065]

22. Reivich KJ, Seligman ME, McBride S. Master resilience training in the U.S. Army. Am Psychol. 2011; 66(1):25-34. [PubMed: 21219045]

23. Cornum R, Matthews MD, Seligman ME. Comprehensive soldier fitness: building resilience in a challenging institutional context. Am Psychol. 2011; 66(1):4-9. [PubMed: 21219042]

24. Peterson C, Park N, Pole N, D'Andrea W, Seligman ME. Strengths of character and posttraumatic growth. J Trauma Stress. 2008; 21(2):214-7. [PubMed: 18404632]

25. Seligman ME, Steen TA, Park N, Peterson C. Positive psychology progress: empirical validation of interventions. Am Psychol. 2005; 60(5):410-21. [PubMed: 16045394]

26. Kent M, Davis MC, Stark SL, Stewart LA. Resilience-oriented treatment for posttraumatic stress disorder: results of a preliminary randomized clinical trial. Journal of Traumatic Stress. 2011; 24(5):591-5. [PubMed: 21898603]

27. Maercker A, Zollner T, Menning H, Rabe S, Karl A. Dresden PTSD treatment study: randomized controlled trial of motor vehicle accident survivors. BMC Psychiatry. 2006; 6(6):29. [PubMed: $16824221]$

28. Wu KK, Li FW, Cho VW. A randomized controlled trial of the effectiveness of brief-CBT for patients with symptoms of posttraumatic stress following a motor vehicle crash. Behav Cogn Psychother. 2014; 42(1):31-47. [PubMed: 23116597]

29. Ehlers A, Clark DM, Hackmann A, McManus F, Fennell M, Herbert C, Mayou R. A randomized controlled trial of cognitive therapy, a self-help booklet, and repeated assessments as early interventions for posttraumatic stress disorder. Arch Gen Psychiatry. 2003; 60(10):1024-32. [PubMed: 14557148] 

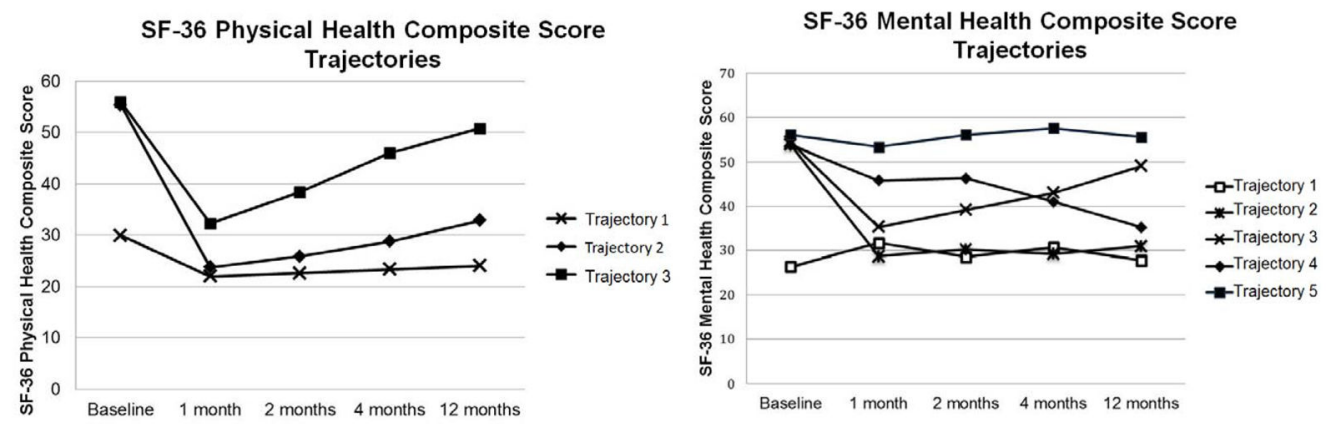

Figure 1.

Trajectories of Physical and Mental Health Scores After Injury. Reprinted from Journal of Surgical Research, Vol 22(1), Ben L. Zarzaur, MD, MPH and Teresa Bell, PhD, Trajectory subtypes after injury and patient-centered outcomes, Pages No.103 - 110, Copyright (2016), with permission from Elsevier. 


\section{Table 1}

Baseline Characteristics

\begin{tabular}{|c|c|c|c|c|}
\hline & $\begin{array}{c}\text { Not High Resiliency } \\
\mathbf{n}=106\end{array}$ & 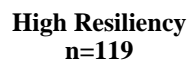 & $\underset{\mathbf{n}=225}{\text { Total Sample }}$ & p value \\
\hline Age Group & & & & 0.752 \\
\hline $18-35$ & $56.6 \%$ & $50.4 \%$ & $53.3 \%$ & \\
\hline $36-45$ & $16.0 \%$ & $21.0 \%$ & $18.7 \%$ & \\
\hline $46-60$ & $17.9 \%$ & $19.3 \%$ & $18.7 \%$ & \\
\hline$>60$ & $9.4 \%$ & $9.2 \%$ & $9.3 \%$ & \\
\hline Gender & & & & 0.160 \\
\hline Female & $46.2 \%$ & $37.0 \%$ & $41.3 \%$ & \\
\hline Male & $53.8 \%$ & $63.0 \%$ & $58.7 \%$ & \\
\hline Race & & & & 0.055 \\
\hline White & $52.8 \%$ & $51.3 \%$ & $52.0 \%$ & \\
\hline Black & $47.2 \%$ & $48.7 \%$ & $47.6 \%$ & \\
\hline Hispanic & $0.9 \%$ & $0.0 \%$ & $0.4 \%$ & \\
\hline Individual Annual Income & & & & 0.020 \\
\hline Less than $\$ 10,000$ & $58.4 \%$ & $42.1 \%$ & $49.8 \%$ & \\
\hline$\$ 10,000$ - less than $\$ 25,000$ & $23.8 \%$ & $26.3 \%$ & $25.1 \%$ & \\
\hline$\$ 25,000$ - less than $\$ 50,000$ & $13.9 \%$ & $16.7 \%$ & $15.3 \%$ & \\
\hline$\$ 50,000$ or more & $4.0 \%$ & $14.9 \%$ & $9.8 \%$ & \\
\hline Insurance Status & & & & 0.175 \\
\hline Insured & $65.1 \%$ & $60.5 \%$ & $62.7 \%$ & \\
\hline Uninsured & $34.9 \%$ & $39.5 \%$ & $37.3 \%$ & \\
\hline Injury Severity Score & & & & 0.766 \\
\hline Less than 15 & $30.6 \%$ & $24.3 \%$ & $27.3 \%$ & \\
\hline $16-24$ & $39.8 \%$ & $41.4 \%$ & $40.7 \%$ & \\
\hline $25-34$ & $25.5 \%$ & $29.7 \%$ & $27.8 \%$ & \\
\hline 35 and greater & $4.1 \%$ & $4.5 \%$ & $4.3 \%$ & \\
\hline Mechanism of Injury & & & & 0.907 \\
\hline Blunt & $73.6 \%$ & $72.3 \%$ & $72.9 \%$ & \\
\hline Penetrating & $18.9 \%$ & $21.0 \%$ & $20.0 \%$ & \\
\hline
\end{tabular}

J Trauma Acute Care Surg. Author manuscript; available in PMC 2018 May 01. 


\section{Table 2}

Multivariate Regression Analysis for High Resiliency

\begin{tabular}{|c|c|c|c|}
\hline Age Group & OR & LCL & UCL \\
\hline $18-35$ & \multicolumn{3}{|c|}{ Reference } \\
\hline $36-45$ & 1.16 & 0.50 & 2.72 \\
\hline $46-60$ & 0.79 & 0.31 & 1.99 \\
\hline Over 60 & 0.48 & 0.13 & 1.75 \\
\hline \multicolumn{4}{|l|}{ Race } \\
\hline White & \multicolumn{3}{|c|}{ Reference } \\
\hline African American & 1.42 & 0.70 & 2.87 \\
\hline \multicolumn{4}{|l|}{ Gender } \\
\hline Male & \multicolumn{3}{|c|}{ Reference } \\
\hline Female & 0.83 & 0.41 & 1.68 \\
\hline Insured & 0.68 & 0.34 & 1.34 \\
\hline Charleston Comorbidity Index & 1.02 & 0.68 & 1.54 \\
\hline \multicolumn{4}{|l|}{ Individual Annual Income } \\
\hline Less than $\$ 10,000$ & \multicolumn{3}{|c|}{ Reference } \\
\hline$\$ 10,001-\$ 25,000$ & 1.97 & 0.90 & 4.30 \\
\hline$\$ 25,001-\$ 50,000$ & 2.55 & 0.97 & 6.70 \\
\hline Over $\$ 50,000$ & 10.92 & 2.58 & 46.32 \\
\hline \multicolumn{4}{|l|}{ Mechanism of Injury } \\
\hline Blunt & \multicolumn{3}{|c|}{ Reference } \\
\hline Penetrating & 1.35 & 0.54 & 3.37 \\
\hline \multicolumn{4}{|l|}{ Injury Severity Score } \\
\hline Less than 15 & \multicolumn{3}{|c|}{ Reference } \\
\hline $16-24$ & 1.30 & 0.61 & 2.77 \\
\hline $25-34$ & 1.42 & 0.62 & 3.26 \\
\hline 35 or greater & 1.47 & 0.29 & 7.56 \\
\hline Hypotensive (systolic blood pressure $<90 \mathrm{mmHg}$ ) & 1.39 & 0.39 & 4.96 \\
\hline
\end{tabular}

J Trauma Acute Care Surg. Author manuscript; available in PMC 2018 May 01. 


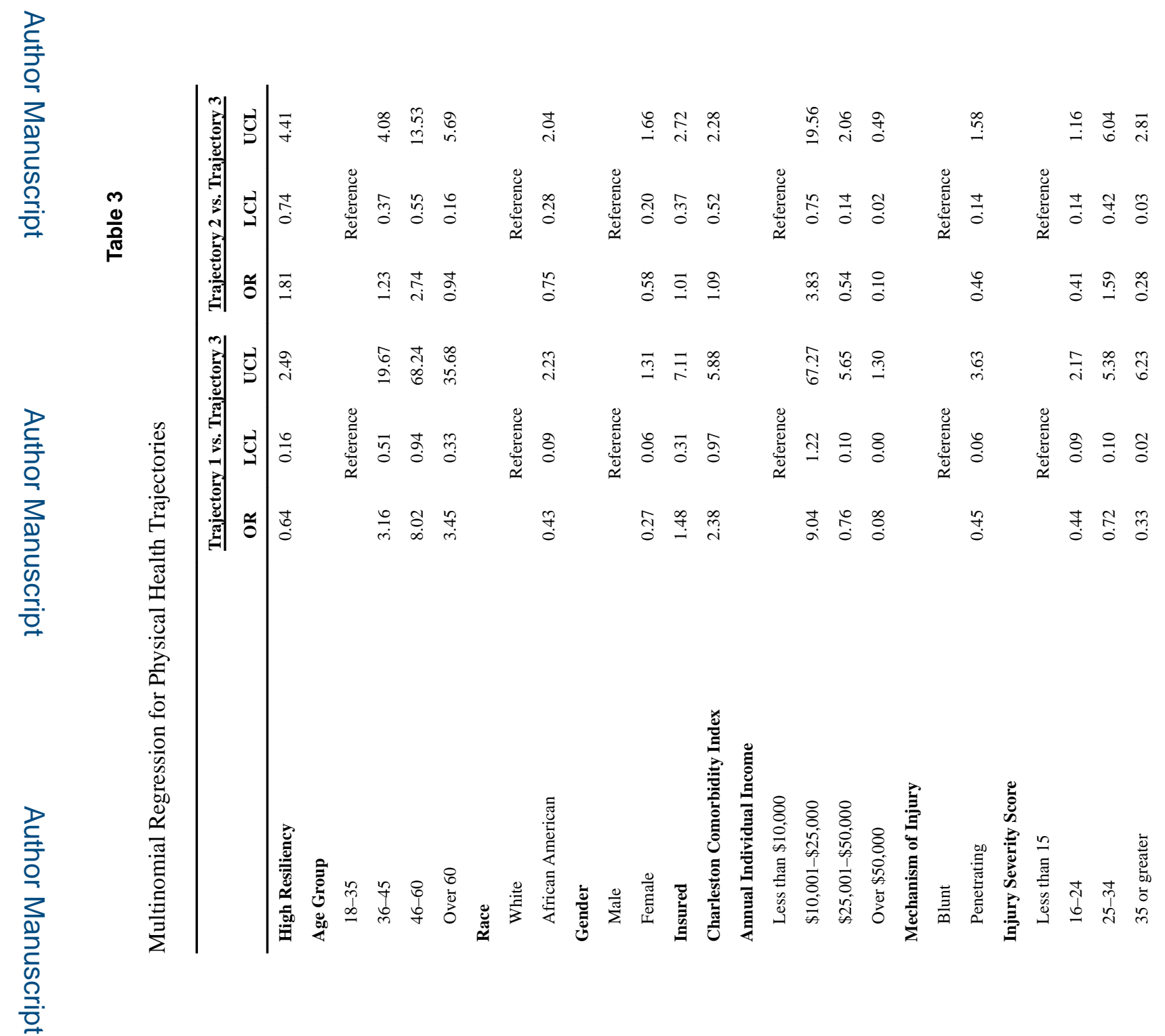

J Trauma Acute Care Surg. Author manuscript; available in PMC 2018 May 01. 

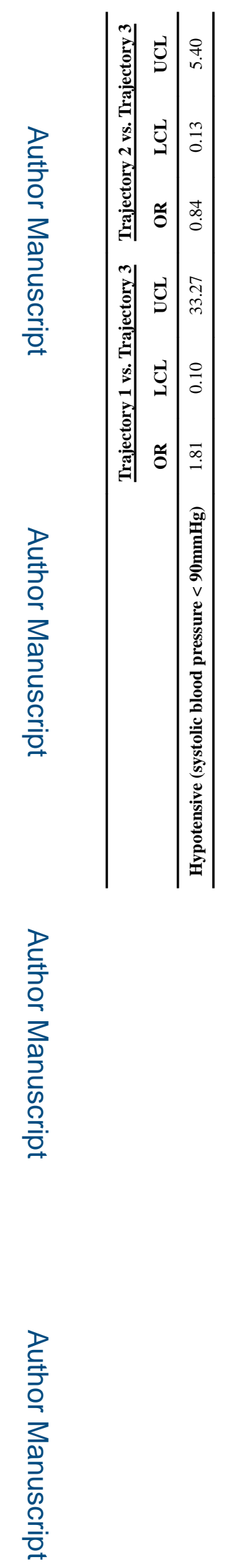


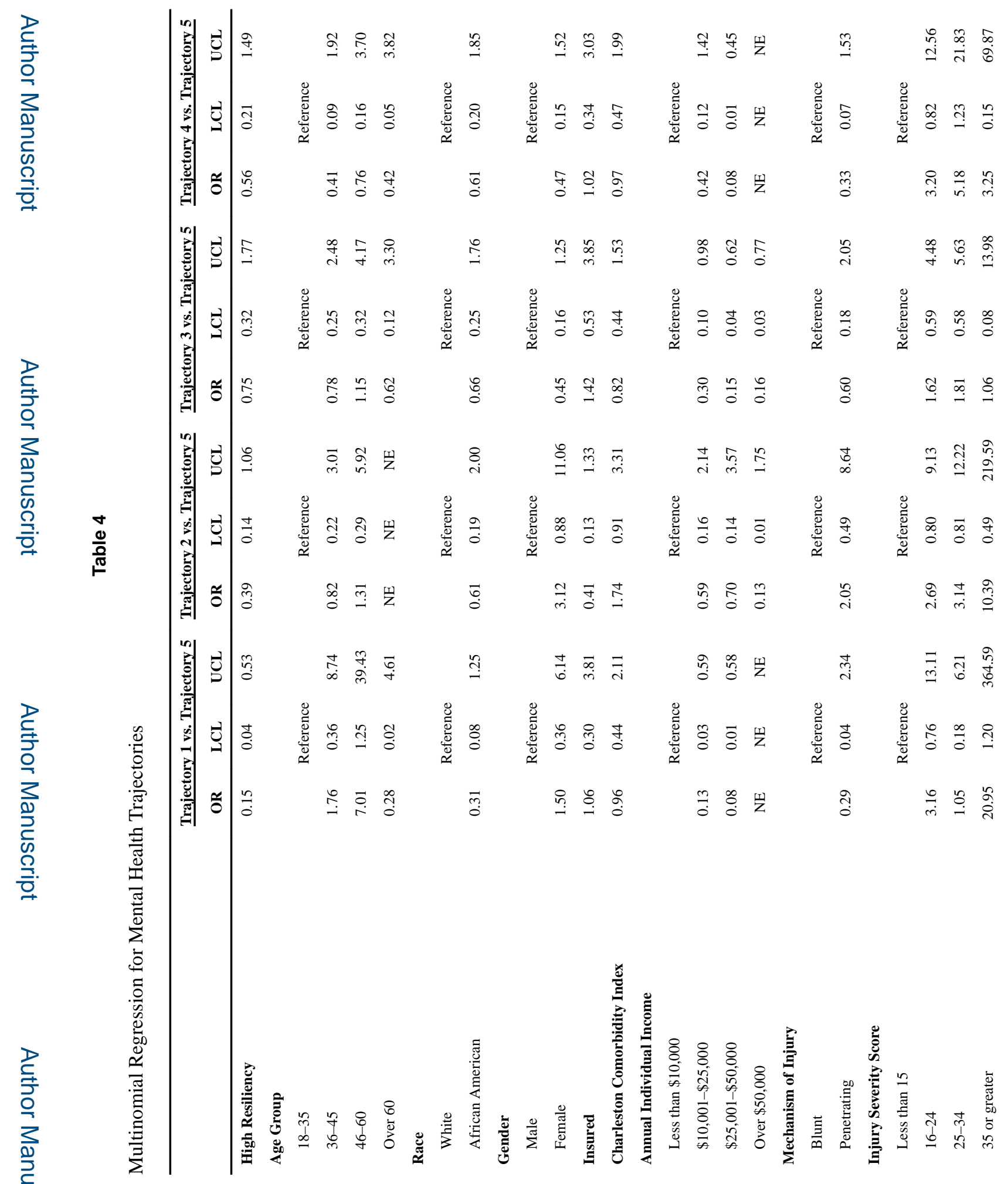

J Trauma Acute Care Surg. Author manuscript; available in PMC 2018 May 01. 


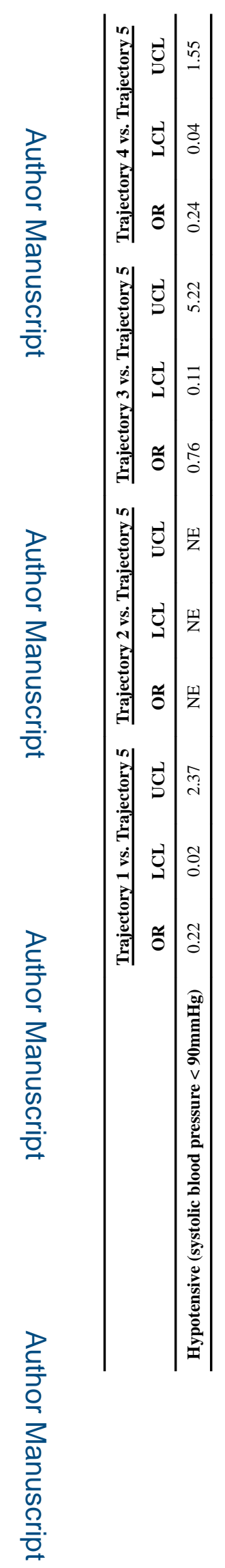


Table 5

Logistic Regression for Long-term Mental Health Outcomes

\begin{tabular}{|l|l|l|l|l|}
\hline & \multicolumn{2}{|l|}{ PTSD OR (95\% CI) } & \multicolumn{2}{l|}{ Depression OR (95\% CI) } \\
\hline & 4 Months & 12 Months & 4 Months & 12 Months \\
\hline High Resilience vs. Not High Resiliency & $0.66(0.27-1.64)$ & $3.18(1.02-9.90)$ & $0.35(0.15-0.79)$ & $0.18(0.06-0.56)$ \\
\hline PTSD vs. No PTSD & NE & NE & $15.07(4.39-51.79)$ & $20.28(4.37-94.14)$ \\
\hline Depression vs. No Depression & $14.57(4.20-50.58)$ & $20.37(4.23-97.98)$ & NE & NE \\
\hline
\end{tabular}

$\mathrm{NE}=$ Not Estimated 